\title{
The Study of Mobility Solution System Design on China Direct Selling Industry
}

\author{
Horng-Jinh Chang, Ta-Ching Lee* \\ Department of Management Sciences, Tamkang University, New Taipei City, Chinese Taipei \\ Email: ${ }^{*}$ TC.Lee@sti.com.tw
}

Received 14 June 2015; accepted 7 July 2015; published 14 July 2015

\begin{abstract}
The article designs a mobility solution for direct selling industry by smartphone. The design of the mobility solution focuses on Mobile Learning (M-Learing) that assists the direct selling company and direct sales to enhance their sales performance and company operation anytime and anywhere with mobile smartphone. It also applies the key concept of enhancing the selling skill to familiar with direct sell company's product anytime. On the other hand, Mobile Learning can play a role of standardization with multi-media contact. In the study, prototype systems were designed with a set of smartphone user interfaces. The study selected two groups of participants: one used existing learning content in personal computer, and another one used the same content with modified format via smartphone, 300 people in total. The evaluation of the result found that there were more than $80 \%$ of mobile solution participants getting higher scores in the evaluation of learning result and 12 times higher visibility of product than traditional way on personal computer. This is a proven mobile solution which can increase the performance of sales in direct selling industry.
\end{abstract}

\section{Keywords}

Direct Selling, M-Learning, Mobile Solution, Mobility, Sales Performance, Smartphone

\section{Introduction}

Mobile device has entered into the mainstream society, affecting many people's daily lives in the recent 5 years. This mature technology is quickly making its presence in many businesses, which accords many opportunities to the learning [1]. The mobile solution can enhance the sales performance and business, which are designed in the study as the M-Learning. It's emergent in the on-job training domain for direct selling industry. Because of the characters of direct company's sales, they are no dedicated working place, office and no dedicated working time to introduce their customers [2]. The direct selling company's sales are wider than other industries. The education level, the working experience, the sales skill and background of communication model are too various between each other. Thus, direct selling company must seek every avenue for improvements to cope with new demands of improving sales performance and execute and monitor sales' selling policy with a new technology.

"Corresponding author. 
Mobile technology seems timely given the nature of today's learning requirements: wider, easy, fast access and interactive without time and place limitation to learning materials and persistent needs for prompt communication. Not surprisingly, new and emerging technologies are being passionately sought after by the speedy growth of smartphone or what we call portable multimedia device to provide better learning mediation for their stakeholders, namely students, educators and end customers. With these formidable learning systems, more and more companies can now seek more efficiency of education on job to let their sales quickly learn and be familiar with their product to sell. Another benefit of such tools is that learning cost incurred unto staff of direct selling company is drastically reduced as independent, self-paced learning can be done outside the company, even to be a product multimedia demonstration tool. Based on these backdrops, it is eagerly anticipated that a new learning approach called mobile learning will be the next major enabler in this decade [3] that will take learning to another level as learning can be literally be conducted on our smartphone thorough wireless technologies [4]. Given the mass technological consumption of this new technology, a new learning paradigm and system design will draw over direct selling industry horizon, bringing in new learning opportunities to this industry.

\section{Purpose}

Design a prototype to prove the concept of mobile solution on direct selling company and their sales.

- Design a system with reasonable and simple architecture for the industry;

- Define and design easy and fitness user interface of mobile devices;

- Define a set operation flows of different roles: User (Sales), learning content administrator (teacher) and publish administer and operator (Direct selling company);

- Define a performance evaluation process and test of the mobile system;

- The Benefit of the study and research for business:

- Increasing younger direct selling sales and alliance agency;

- Increasing new staff to understand and familiar with products anytime and anywhere;

- Decreasing the critical mistaking of product profile briefing in the pre-selling phase;

- Reducing the cost of training and multi-language effort.

\section{Literature Review and Assumption Derivation}

\subsection{Direct Selling}

According to the Administration of Direct Selling Regulations of China, direct selling refers to the sales mode of the direct marketing and selling of products by direct selling personnel recruited by direct selling enterprises to final consumers away from fixed business locations.

Li (2005) [5] suggests that direct selling can be explained in broad and narrow senses. In a broad sense, direct selling refers to a sales mode with no fixed or permanent sales location, including online sales, TV shopping, mail order, and personal selling. In a narrow sense, direct selling, also known as personal selling, is a sales mode of marketing and selling products or services by independent salespeople through face-to-face demonstrations or displays away from fixed locations. Wang Yuben of the Research Center for Direct Selling at Peking University proposes that direct selling comprises at least three dimensions such as the absence of a store, which means sales do not take place in the market in the traditional sense; the directness of products reaching the final consumers; and the directness of human bonding through products. These definitions are similar to the ones used in many other countries, the key definition being sales without a fixed location through independent salespeople and, in the sale of products, through displays and demonstrations.

\subsection{Mobile Learning}

Mobile learning (M-Learning) is meant the student can take a portable or mobility device to browse content at anytime, anywhere with synchronization or pre-download to study what he wants. The multimedia content and interactive content can not only show in personal computer, but also fixable to display in smartphone, such as Android and iPhone in recent years. Based on the study of Ta-Cheng Lin, Tzung-Shi Chen, Properties of M-Learning are identified by Chen et al. [6] and Chiu et al. [7] as following: 1) Urgency of learning need; 2) Initiative of knowledge acquisition; 3) Mobility of learning setting; 4) Interactivity of learning process; 5) Situating of instructional activity; 6) Integration of instructional content; In an education of a company and on-job 
training, those of properties are more significant for their staff, due to their personal performance. Therefore, context-aware without location restriction, M-Learning will be personalization of learning knowledge and Adaptability of learning.

Most of research and study of Mobile learning are focused on field trip [8]-[10], those studies are traditional ways to enhance facilities of and provide an introduction boards to aid student learning. This kind of mobile learning can be enhanced the learning target or goods to be remembered. But this mobile learning is restricted by location and time as the same as traditional text book. In This paper, the mean of M-Learning are dedicated on learning in mobile device. For a student or a sales people in a company, the context is meant location, people, customer and situation, that they have to perform their adaptive selling sill to provide as their customer wants. $\mathrm{Ni}$, Liu, Lau and Patil [11] fingers out the entity which will impact the student can be defined as a context. The Mobile device with mobile content can be identified a context to inference to sales behavior on selling. Especially in direct selling industry, Adaptive selling is defined as modifying oneself to fit the environment to achieve sales goals. Weitz (1986) [12] argued that stressing the adaptive approach can enhance the efficiency of salespeople, which is echoed by other researchers and ability tutors. For instance, Erika (1999) [13] pointed out that empathy, one of the ten most prominent traits of top salespeople, is a presentation of adaptive selling. In a study of successful and unsuccessful salespeople conducted by Baker (1999) [14] in Canada, seven criterianamely, output performance, technical knowledge, sales ability, adaptability, teamwork, sales planning, and sales backup - were used to evaluate the performance of salespeople. Among the criteria, adaptability stood out as the most effective and consistent dimension that distinguishes high and low performance. Therefore, based on Horng-Jinh Chang, Ta-Ching Lee [1], the mobile solution can be enhanced adaptive selling behavior and sales performance, the mobile learning are studying and designing in many literatures. From the study of Mohamed, Laila [15], several research has been done on M-Learning environment including requirements design [16], architecture [17], M-Learning model [18] and current trend [19]. Also there are some applications in the market that enable companies to manage their online quizzes and monitor their students' progresses online. For direct Selling industry, some of famous direct selling companies are built up their owner e-education and e-learning system to be an intelligent mobile tutoring tool for teachers that supports interaction and educating dialogue using mobile technologies. It helps teachers in managing their tutors' activities using web and mobile technologies. It also supports communications between students and their teachers using either the system on mobile devices or personal computers. Furthermore, the platform can support student to show company's product on their mobile device to their customer without any human mistake and context influence. A context-aware mobile and collaborative learning scenario [20] is a context-aware mobile application for university that supports many universities campus requirements such as in the beginning of each session, the attendance list is filled automatically during sessions, lecture materials are loaded in a student hand-held device. The same scenario can be applied into direct selling industry. The company can check their sales and staff to verify the status of learning. Product's brief data of company can be loaded as a sales tool for them via M-Learning system.

\section{Research Method}

The purpose of this article is to reflect on and understand the position of mobile learning in direct selling company for sales. The bulk of this article is primarily an analysis of the literature about mobile learning. Based on literatures and discussion with a direct selling company in China, The study designed a system function and prototype to provide those sales to be a participator. After those selected sales used the E-learning prototype, those participated were examine by a set of question of the company's product profiles. The result of the evaluation was to assume the result of sales performance with and without M-Learning support (Figure 1).

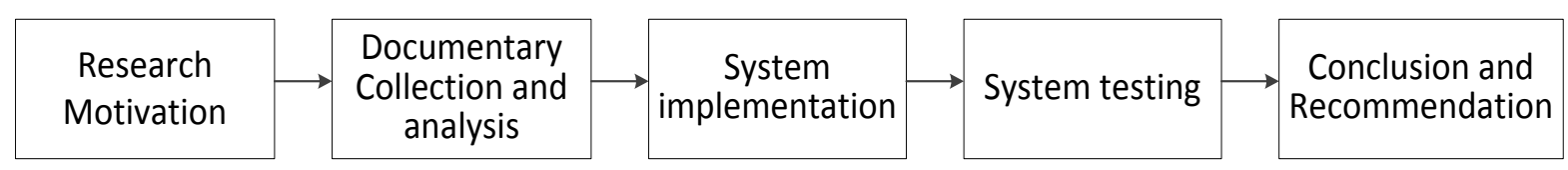

Figure 1. Designed framework.

\section{System Design (Figures 2-13)}




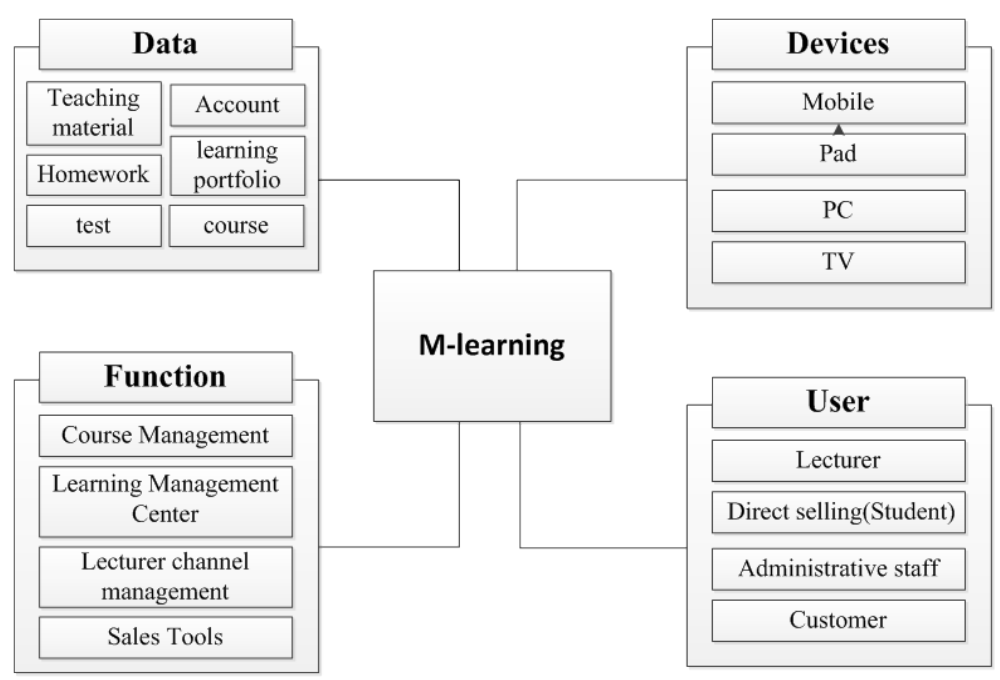

Figure 2. Mobile learning system architecture.

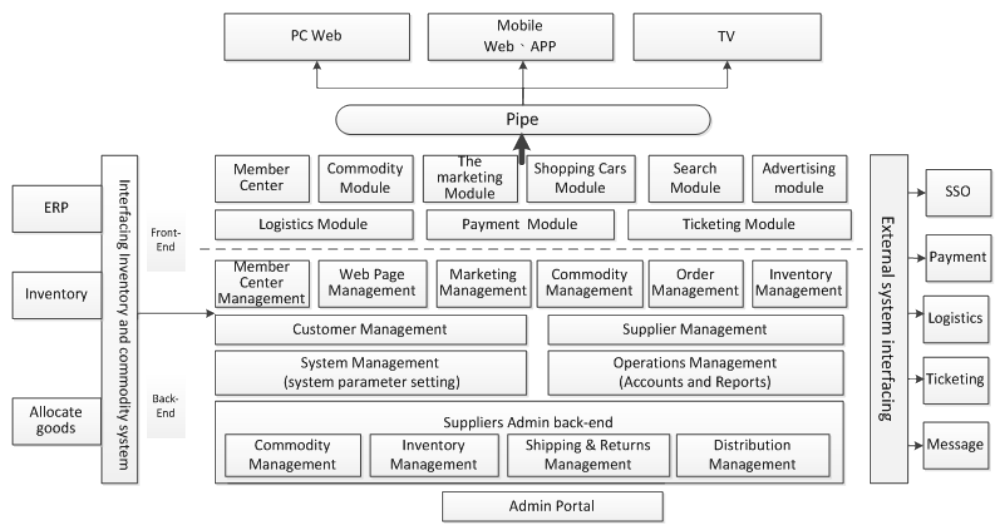

Figure 3. Mobile learning function block.

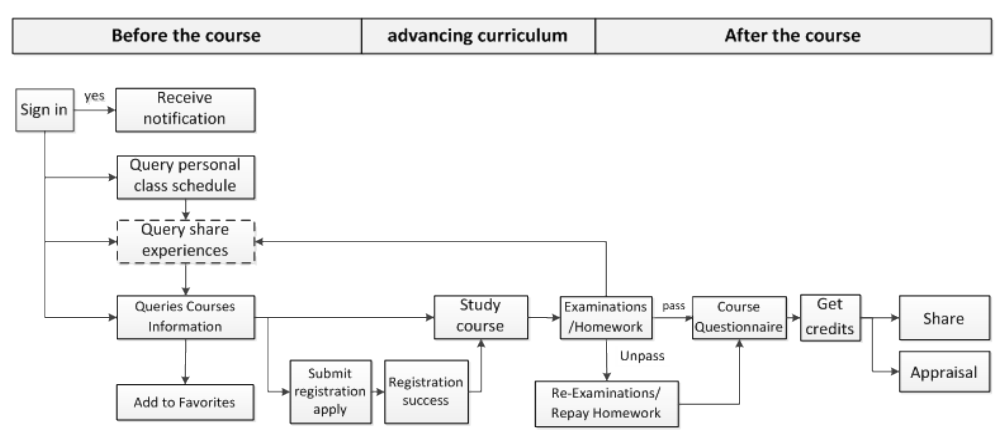

Figure 4. For direct selling sales.

\section{Result Evaluation}

In order to evaluate the effect of mobile solution, this research was conducted from May, during which direct selling company in China. Some of their sales businesses were evaluated and tested after they used the Mlearning prototype in smartphone. Others used multimedia and existing learning system in their personal computers and notebooks. The evaluation were collected from 300 sales employed in the direct selling company in china. 150 of them were designed to use M-Learning prototype via there owned smartphone. Another 150 of them were designed to use personal computer and notebook with multimedia, picture, document of products. 35 


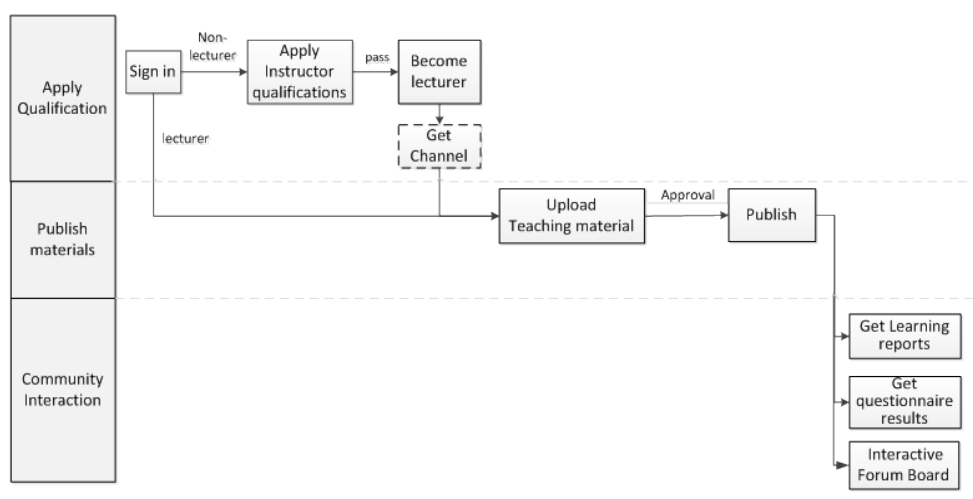

Figure 5. For direct selling teacher.

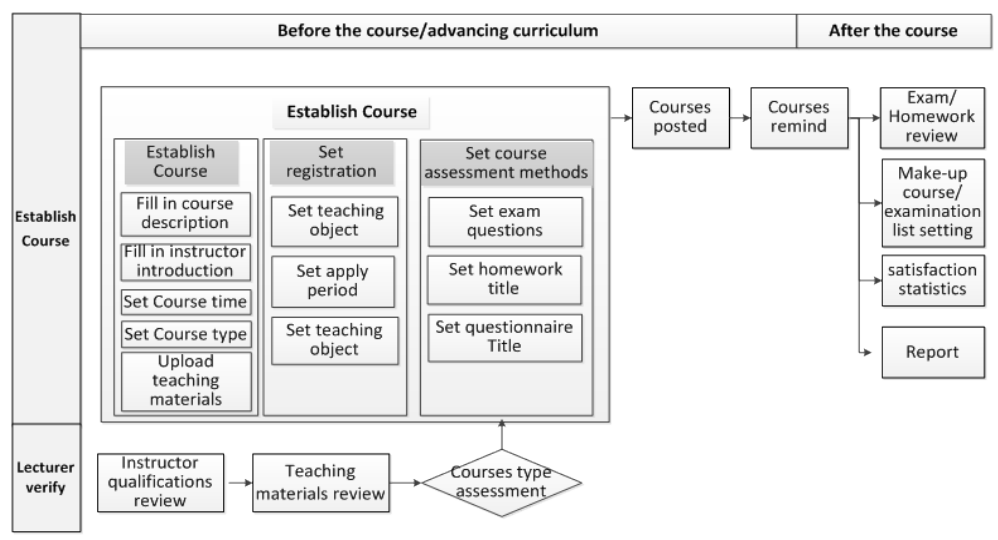

Figure 6. For direct selling operator in company.

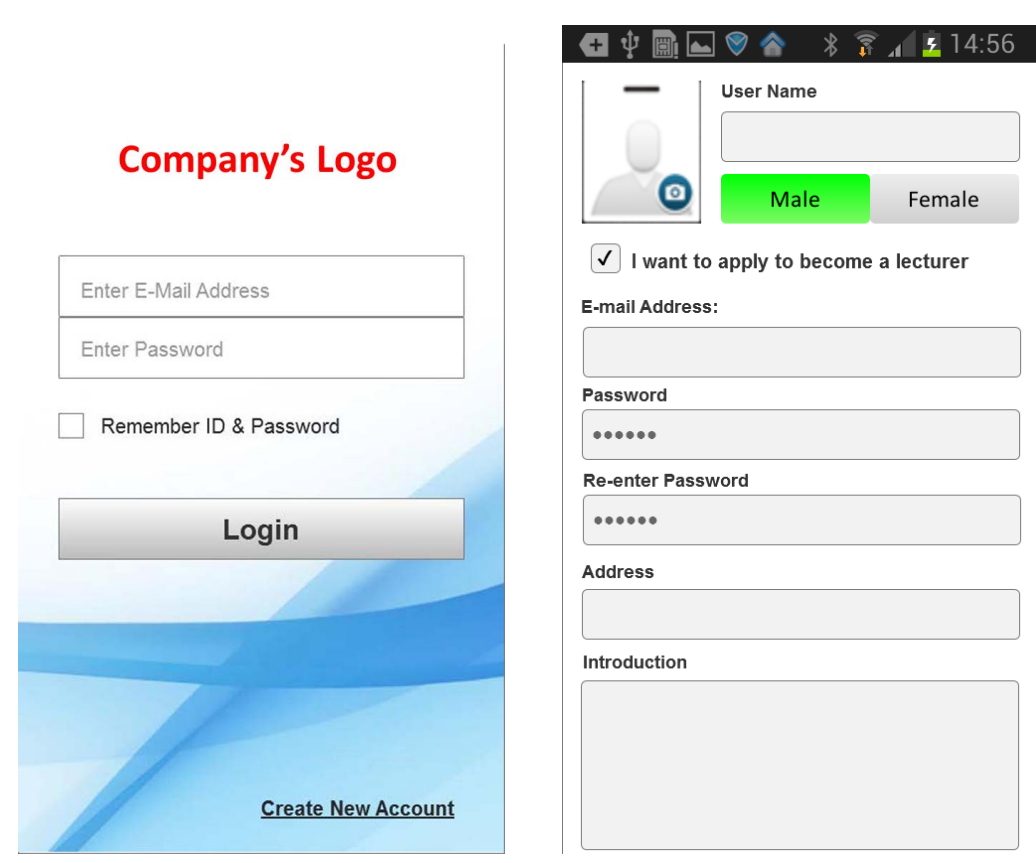

Figure 7. Login and subscription User Interface.

products' pictures and profiles of the direct selling company were set into the M-Learning prototype for the group of mobile solution participates. The same products' data were created as pictures, documents for the 


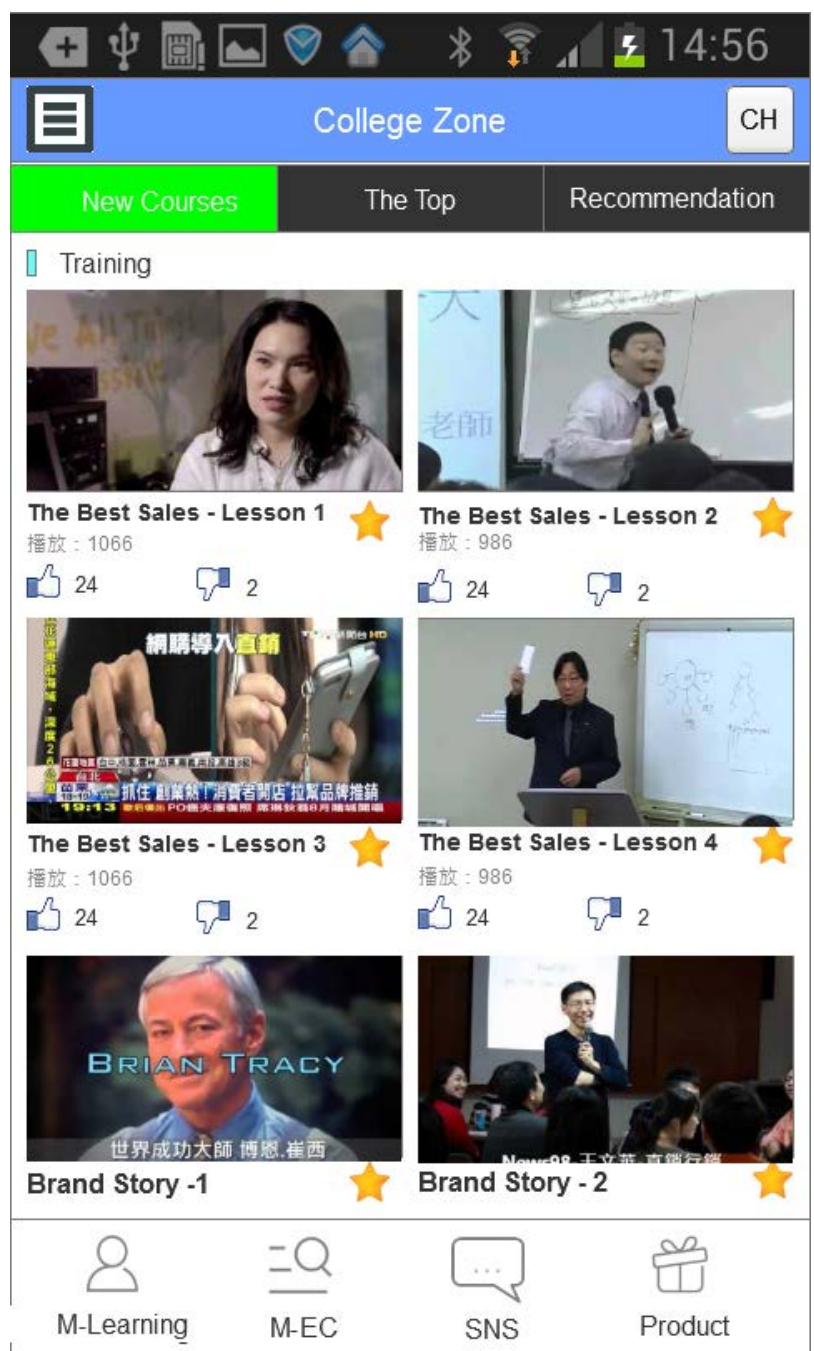

Figure 8. Product multimedia catalog.

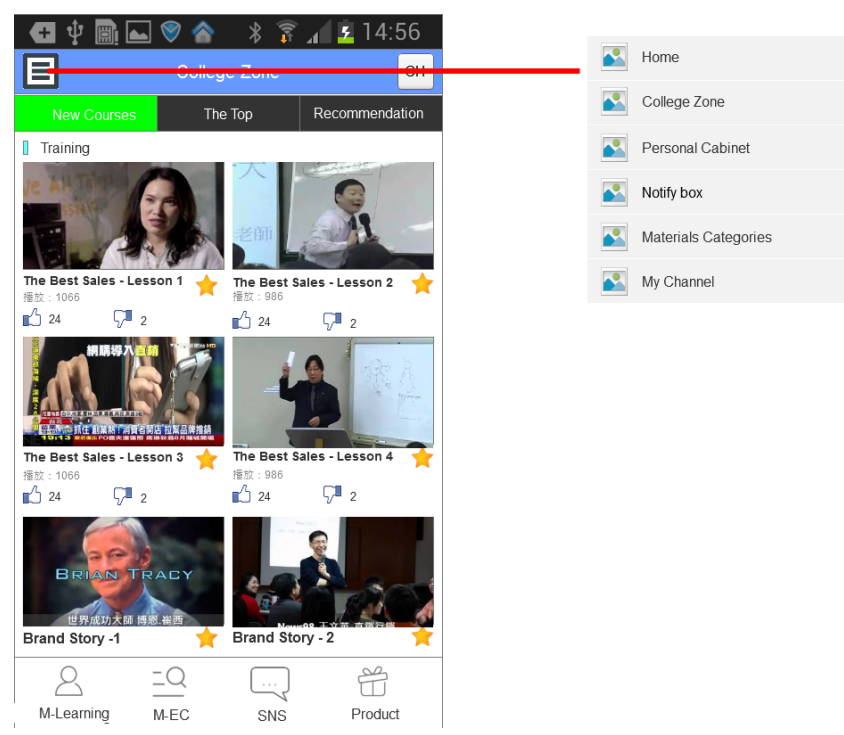

Figure 9. Catalog with multifunction with an easy pull-down menu. 

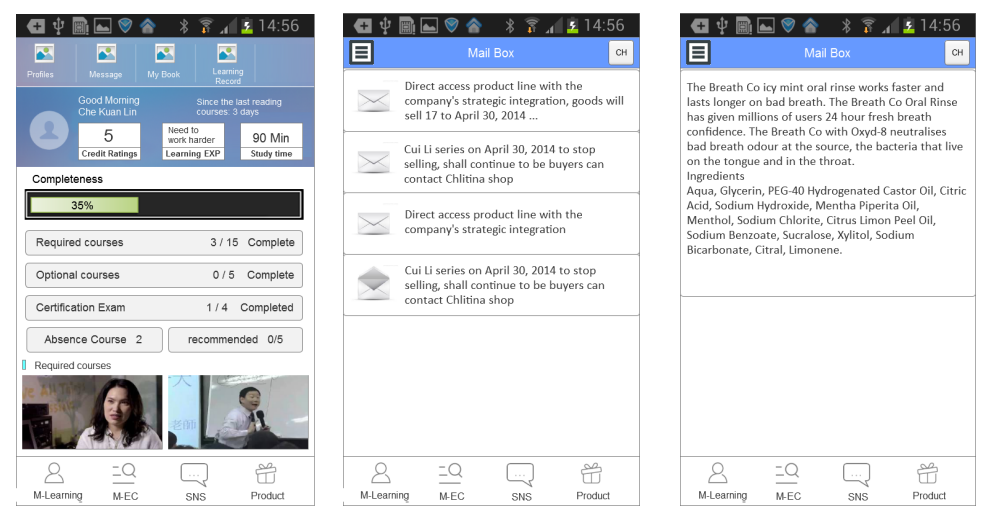

Figure 10. Sales personalization Learning status tacking and review.
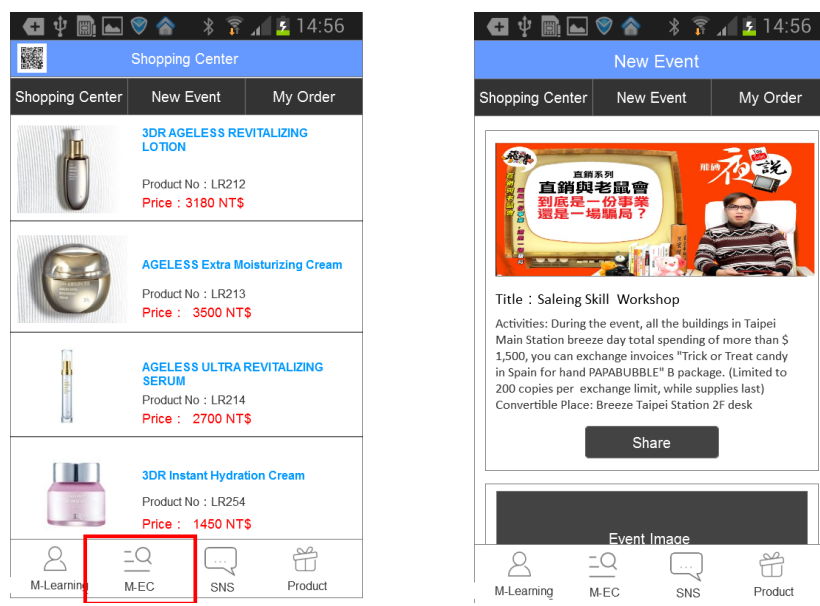

Figure 11. Sales training with product/Evan profile and briefing.

\begin{tabular}{|c|c|c|}
\hline \multicolumn{3}{|c|}{ My Order } \\
\hline Shopping Center & New Event & My Order \\
\hline
\end{tabular}

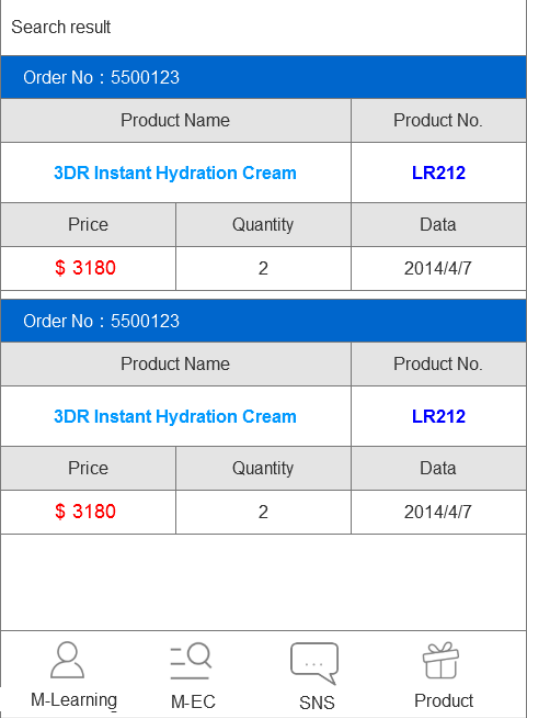

Figure 12. Customer pre-order assister for sales. 


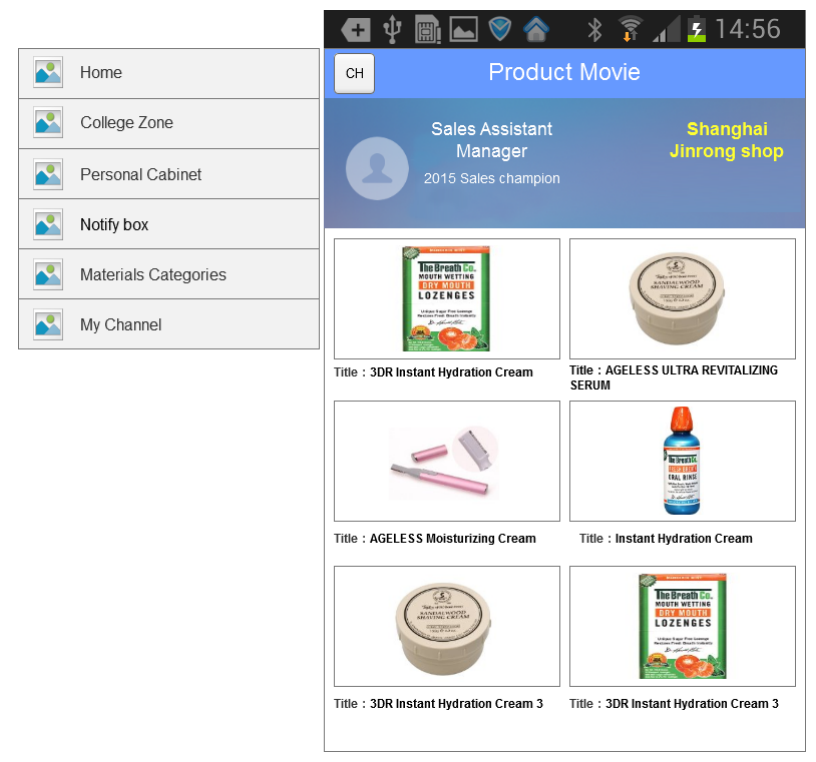

Figure 13. Sales training with personal review file.

group of personal computer and notebook's participates.

The learning period is 2 days to let all of participates remember all of product's profile and major key function, benefit for the portion of learning evaluation. After that, the study performed a test to let all participates fill 35 direct selling products as test questions. The result showed that $80 \%$ of mobile solution participates can fill right answers into 35 questions with lease than 2 error answers. On the other hand, there was about $30 \%$ of personal computer and notebooks' participates can fill right answers with lease than 2 error answers. Another evaluation is the product click rate which is meant the amount of view on products that can be a population rate of products. The study was designed 35 products to show in both of M-Learning solution and existing solution. The data collection period is 2 days to let all of participates browse products anytime, anywhere with their smartphones or personal computers. The result showed that the product browsing rate of mobile participates was 12 times than participates who used personal computers and notebooks. Both of evaluation result on M-Learning via smartphone is proven that is more effective than existing systems via personal computer and notebooks.

\section{Conclusions and Future Work}

The design of mobile applications is not an easy task. There are a variety of platforms and technologies to choose from. Mobile devices resources are limited. User experience with mobile devices and software is various. However, in this decade of technology, most of people can use smartphone in their daily life. People have easy access to familiar process which is easier than browsing in their computers. According to the study and evaluation as above, the effective of mobility solution can be proven with real user case that it can solve most of problems in direct selling industry and enhance the existing business.

The future study and challenges of mobility solution can be suggested in direct selling business as follows:

- Using cloud IaaS to reduce the cost of company;

- Making it easier to cheat and share with others;

- Creating universal user interface to easy hands-on;

- Designing an effective context aware mobile application;

- Enhancing the security in the solution;

- Preventing the disclosing of the confidential information via network;

- Reducing additional learning curve for non-technical learners;

- Enabling the use of M-Learning application across mobile platform;

- Creating a feeling of isolation, separation or of being out-of-the-loop;

- Rendering some content outdated because of rapid upgrades (here today, outdated tomorrow);

- Enhancing user experience data collection to optimize the system and user interface. 


\section{References}

[1] Hanafi, F. and Samsudin, K. (2012) Mobile Learning Environment System (MLES): The Case of Android-Based Learning Application on Undergraduates' Learning. International Journal of Advanced Computer Science and Applications, 3, $1-2$.

[2] Chang, H.J. and Lee, T.-C. (2015) An Efficiency Prediction of Mobility Solutions in Direct Selling Businesses of Mainland China. The 2015 International Conference in Management Sciences and Decision Making.

[3] Keegan, D. (2002) The Future of Learning: From E-Learning to M-Learning. http://learning.ericsson.net/leonardo/thebook/chapter4.html\#milearn

[4] Barbosa and Geyer (2005) Pervasive Personal Pedagogical Agent: A Mobile Agent Shall Always Be a Learner. Proceeding of IADIS International Conference Mobile Learning, Malta, 281-285.

[5] Bobnano Aizheng, L. (2005) Study of the Theory and Application of Direct Commerce in China. Tianjin University.

[6] Chen, Y.S., Kao, T.C. and Sheu, J.P. (2003) A Mobile Learning System for Scaffolding Bird Watching Learning. Journal of Computer Assisted Learning, 19, 347-359. http://dx.doi.org/10.1046/j.0266-4909.2003.00036.x

[7] Chiu, P.-S., Kuo, Y.-H., Huang, Y.-M. and Chen, T.-S. (2008) A Meaningful Learning Based u-Learning Evaluation Model. Proceedings of the 8th IEEE International Conference on Advanced Learning Technologies, Cantabria, July 2008, 1-5.

[8] Markett, C., Sanchez, I.A., Weber, S. and Tangney, B. (2006) Using Short Message Service to Encourage Interactivity in the Classroom. Journal of Computers \& Education, 46, 280-293. http://dx.doi.org/10.1016/j.compedu.2005.11.014

[9] Motiwalla, L. (2005) Mobile Learning: A Framework and Evaluation. Computers \& Education, 49, 581-596. http://dx.doi.org/10.1016/i.compedu.2005.10.011

[10] Wessels, A., Fries, S., Horz, H., Scheele, N. and Effelsberg, W. (2007) Interactive Lectures: Effective Teaching and Learning in Lectures Using Wireless Networks. Computers in Human Behavior, 23, 2524-2537. http://dx.doi.org/10.1016/j.chb.2006.05.001

[11] Ni, L.M., Liu, Y., Lau, Y.C. and Patil, A.P. (2004) LANDMARC: Indoor Location Sensing Using Active RFID. Wireless Networks, 10, 701-710. http://dx.doi.org/10.1023/B:WINE.0000044029.06344.dd

[12] Barton, A.W., Sujan, H. and Sujan, M. (1986) Knowledge, Motivation, and Adaptive Behavior: A Framework for Improving Selling Effectiveness. Journal of Marketing, 50, 174-191. http://dx.doi.org/10.2307/1251294

[13] Erika, R. (1999) The 10 Traits of Top Salesperson. Sales and Marketing Management, 151, 34-37.

[14] Baker, W.E. and Sinkula, J.M. (1999) The Synergistic Effect of Market Orientation and Learning Orientation on Organizational Performance. Academy of Marketing Science Journal, 27, 411. http://dx.doi.org/10.1177/0092070399274002

[15] Sarrab, M., Elgamel, L. and Aldabbas, H. (2012) Mobile Learning (M-Learning) and Educational Environments. International Journal of Distributed and Parallel Systems (IJDPS), 3. http://dx.doi.org/10.5121/ijdps.2012.3404

[16] Parson, D., Ryu, H. and Cranshaw, M. (2006) A Study of Design Requirements for Mobile Learning Environments. Proceedings of the Sixth International Conference on Advance Learning Technologies.

[17] Sharma, S. and Kitchens, F. (2004) Web Service Architecture for M-Learning. Electronic Journal on E-Learning, 2.

[18] Barker, A., Krull, G. and Mallinson, B. (2005) A Proposed Theoretical Model for M-Learning Adoption in Developing Countries. 4th World Conference of M-Learning.

[19] Ting, R.Y.-L. (2005) Mobile Learning-Current Trend and Future Challenges. Proceedings of the fifth IEEE ICALT'05.

[20] Jihen, M., Mona, L., Alain, D. and Ghezala, H.B. (2007) A Context Aware Mobile and Collaborative Learning Scenario. IEEE Multidiscip. Engineering Educ. Mag., 2, 65-69. 